\title{
Social Aspects of Wind Power Generation- A Review
}

\author{
${ }^{1}$ G. C. Biswal, ${ }^{2}$ S. P. Shukla \\ ${ }^{1,2}$ Department of Electrical Engineering, BIT,Durg(India)
}

\begin{abstract}
Wind energy, commonly recognized to be a clean and environmentally friendly renewable energy resource that can reduce our dependency on fossil fuels, has developed rapidly in recent years. Its mature technology and comparatively low cost make it promising as an important primary energy source in the future. However, there are potential environmental impacts due to the installation and operation of the wind turbines that cannot be ignored. This paper aims to provide an overview of world wind energy scenarios, the current status of wind turbine development, development trends of offshore wind farms, and the social, environmental and climatic impact of wind farms.
\end{abstract}

Key Words: wind power, aesthetics, tower-spacing, emissions, environmental benefits

\section{Introduction}

Wind Energy India is a growing sector of renewable energy source. According to Indian Wind Energy Association (IWEA), the wind energy sector in India is ranked 5th in the world and has an installed capacity of approx. 22,000 Megawatt energy (see table: 1 below). Therefore, wind energy India is beginning to play a key role. Wind power represents one of the most widespread and commercially viable renewable energy generation technologies, gaining significant levels of deployment across both the developing and industrialised world. Most of the wind energy deployment is grid connected.

Table 1: Renewable Power capacity in India [1]
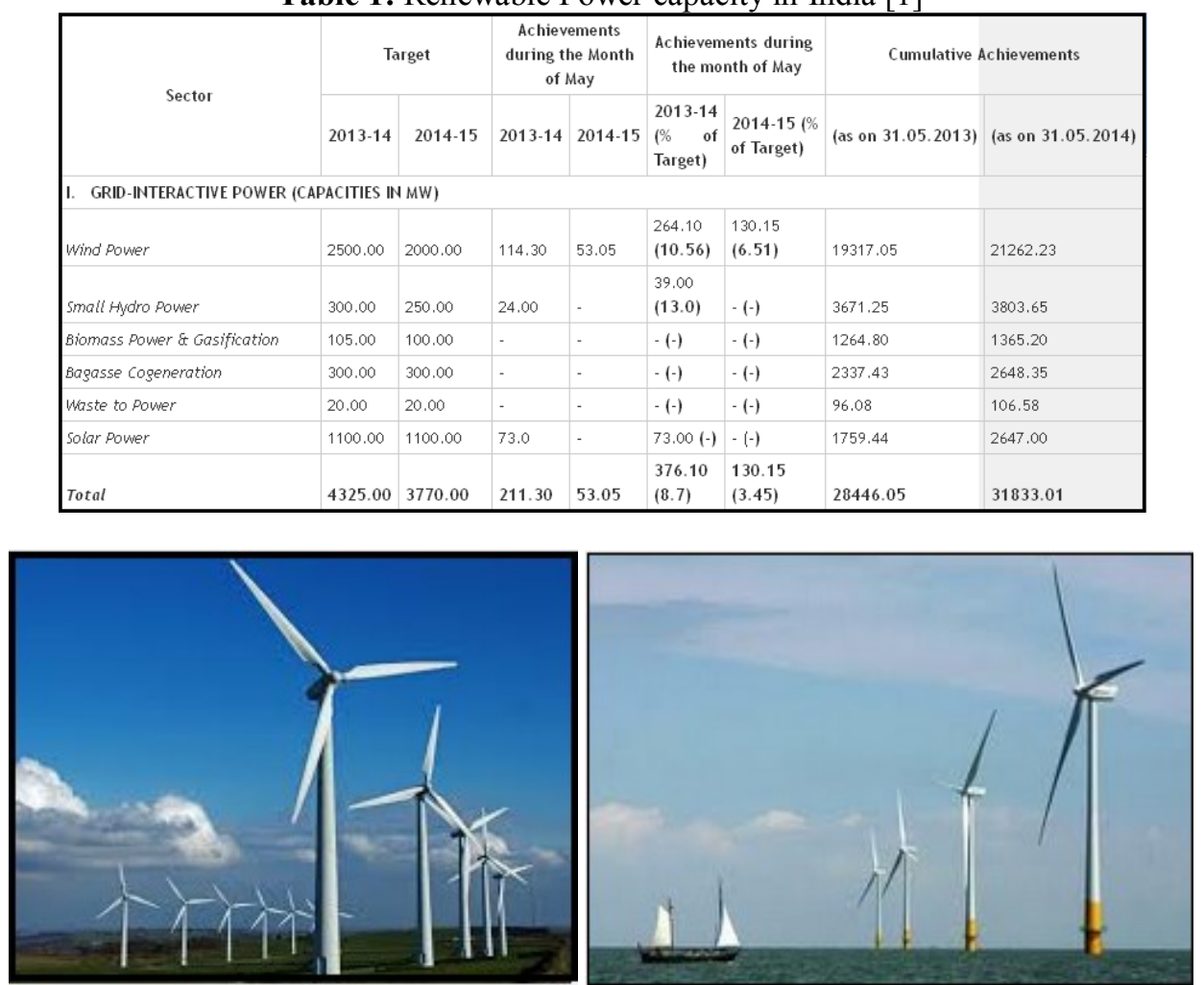

Figure 1: Wind farms on land and Offshore

Figure 1 above gives pictorial view of the two types of wind farms. The first is installed on land while the other is in the sea also called as offshore wind farm.

Wind energy has significant potential to reduce GHG(Green House Gases) emissions, together with the emissions of other air pollutants, by displacing fossil fuel-based electricity generation.[2] Because of the commercial readiness and cost of the technology, wind energy can be immediately deployed on a large scale.As 
with other industrial activities, however, wind energy also has the environmental benifits of wind energy come primarily from displacing the emissions from fossil fuel-based electricity generation.

However, the manufacturing, transport, installation, operation and decommissioning of wind turbines induces some indirect negative effects, and the variability of wind power output also impacts the operations and emissions of fossil fuel-fired plants. Such effects need to be subtracted from the gross benifits of wind energy in order to estimate net benifits these latter effects are modest compared to the net GHG reduction benifits of wind energy.

Depending on the characteristics of the electric system into which wind energy is integrated and the amount of wind energy supply, the reduction of air pollution and GHG emissions may be substantial. Globally, it has been estimated that roughly $500 \mathrm{GW}$ of wind power capacity would be installed by the end of 2017 . Green House Gases

Social Aspects - Environmental Aspects [3]:
1. Land Area and Use
2. Acoustics
3. Wild Life
5. Emissions
4. Electromagnetic Interference
6. Erosion of Land Area
7. Spacing between the turbines
08. Environmental Aspects
9. The useful land between turbines
10. Health and Safety

\section{Some important points are enlightened below:}

(i) Landscape and land use:

Wind turbines are tall structures which ideally need to operate in an exposed site where they can make best use of the prevailing wind. This means they are likely to be visible over a relatively wide area. Whether this has a detrimental effect is highly subjective. Being visible is not the same as being intrusive (see fig.2 below).

While some people express concern about the effect wind turbines have on the beauty of our landscape, others see them as elegant and graceful, symbols of a better, less polluted future the landscape is largely humanmade and has evolved over time. Changes to the visual appearance of the countryside, Such as roads or lines of electricity pylons, which were once considered intrusions, are now largely accepted as part of the view.
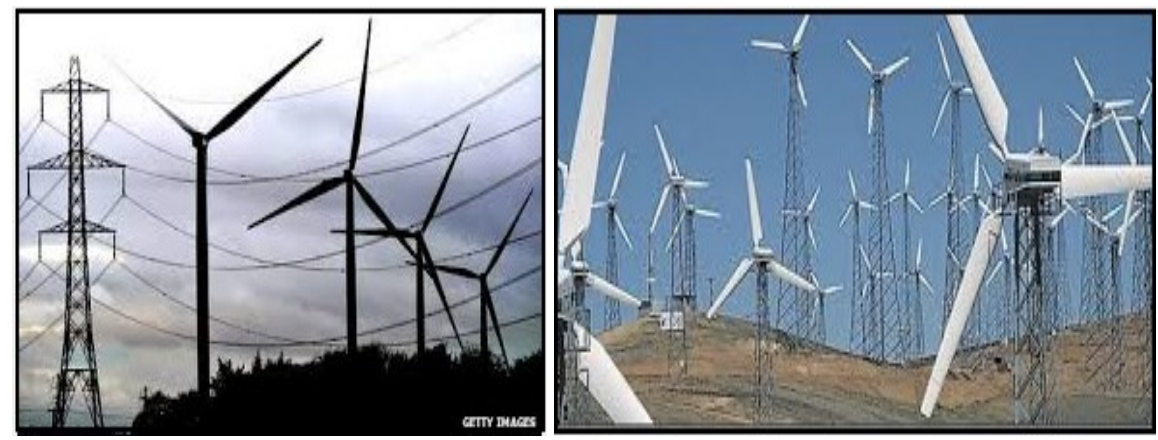

Figure 2: Wind farms landscape

Wind turbines can be removed easily when decommissioned, and the landscape returned to its previous condition. Most countries have established rules which exclude certain areas, such as national parks or nature reserves, from development. Others have identified priority areas where wind power is specifically encouraged through strategic planning guidelines.

\section{(ii)Wild Life:}

Animals and birds can be affected by wind energy development through loss of habitat, disturbance to their breeding and foraging areas and by collisions caused by the rotating turbine blades. Compared to other causes of mortality among birds, however (see fig. 3 below), the effect of wind power is relatively minor. Well publicised reports of bird deaths at sites including the Altamont Pass (San Francisco) and Tarifa in southern Spain, are not indicative of the experience at the thousands of wind energy developments now operating around the world[4]. 

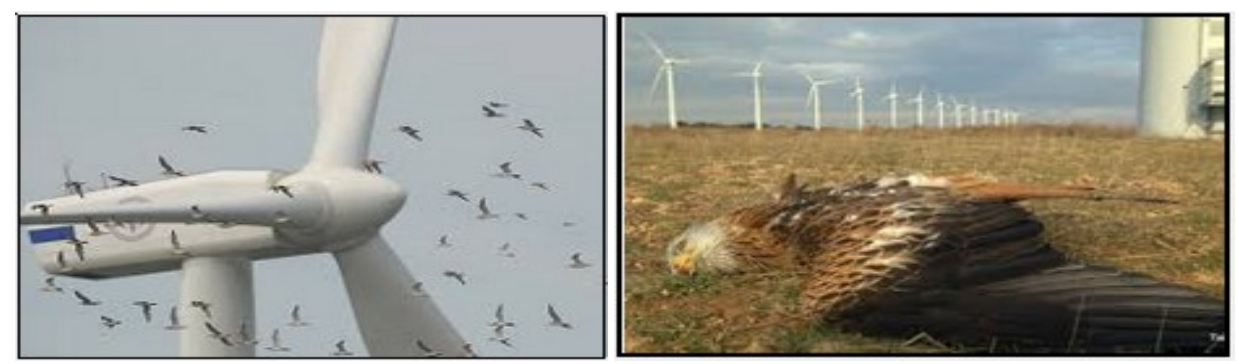

Figure 3: Wind farms killing the bird

\section{(iii) Environmental Benefits:}

Effects of wind energy is system specific, but can in general be documented by the difference in estimated external costs for wind energy and other electricity supply options. Monetized figures for climate change damages, human health impacts, and material damages and agricultural losses show significant benefits from wind energy.
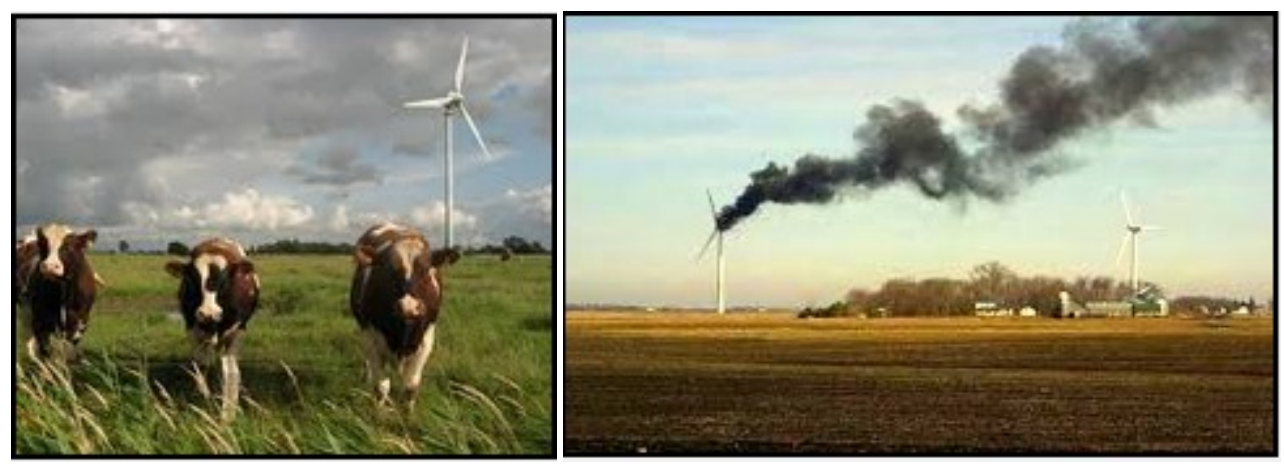

Figure 4: Wind farms and environmental concern

It also qualitatively assesses the direction of possible impacts associated with other damage categories (ecosystem effects, large accidents, security of supply and geopolitical effects), finding that the net benefits of RE sources tend to be underestimated by not including these impacts in the monetized results.

The environmental damages associated with other forms of electricity generation and benefits associated with wind energy have been summarized many times in the broader externalities literature. The conclusion is mixed useful as well as harmful (see fig. 4 above).

\section{(iv)Electromagnetic Interference:}

The increase in the number and size of wind farms, leads inevitably to an increased possibility of interference with nearby radio communication, aircraft navigation and radar systems (as shown in fig. 5 below). [5]

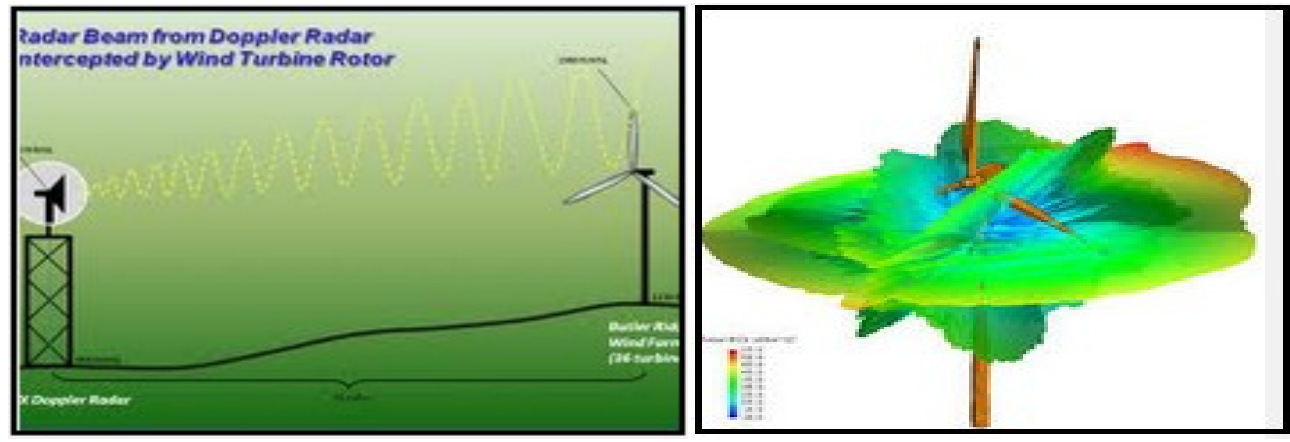

Figure 5: Wind farms and Electromagnetic Interference

The layout during the design phase of a wind farm, according to criteria of radio impact, involves a long series of benefits for the developers. These benefits justifiably outweigh the economic investment required for the analysis of the relevant interference studies. 


\section{(V) Emissions:}

The environmental impact of wind power for land-based wind turbines, compared to the environmental impacts of traditional energy sources, is relatively minor. It is slightly higher than the environmental impact of hydro power on a life-cycle basis. Unlike electricity derived from fossil fuel and nuclear power plants, wind power does not use fuel or employ a fueling cycle, thus emitting no air pollution or greenhouse gases.

While a wind farm may cover a large area of land, many land uses such as agriculture are compatible with it, as only small areas of turbine foundations and infrastructure are made unavailable for use.

Those opposed to wind turbines make a remarkable claim about this form of generation: that the energy and materials required to manufacture it, and the concrete required for the base during construction emit so much $\mathrm{CO} 2$ that wind turbines never pay the carbon debt back. Figure 6 below represents the reduction in CO2.[6]
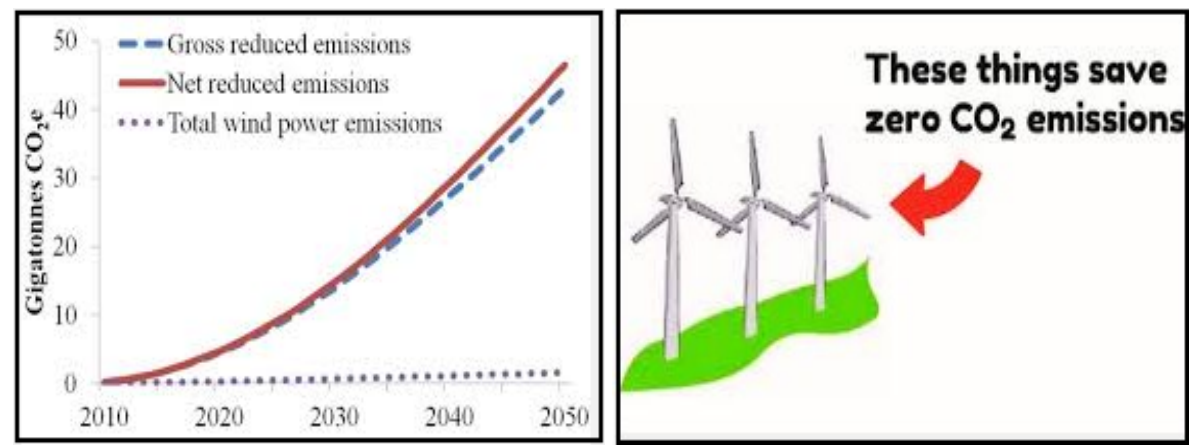

Figure 6: Wind farms and Emissions

\section{(VI) Erosion of Land Area:}

Wind systems can involve the transportation of large and heavy equipment. This can cause a large temporarily disturbed area near the turbines. Erosion is another potential environmental problem that can stem from construction projects. The single most reliable technique for limiting erosion is to avoid grading roads and to perform site reclamation post construction (shown in fig.7 below).[7]
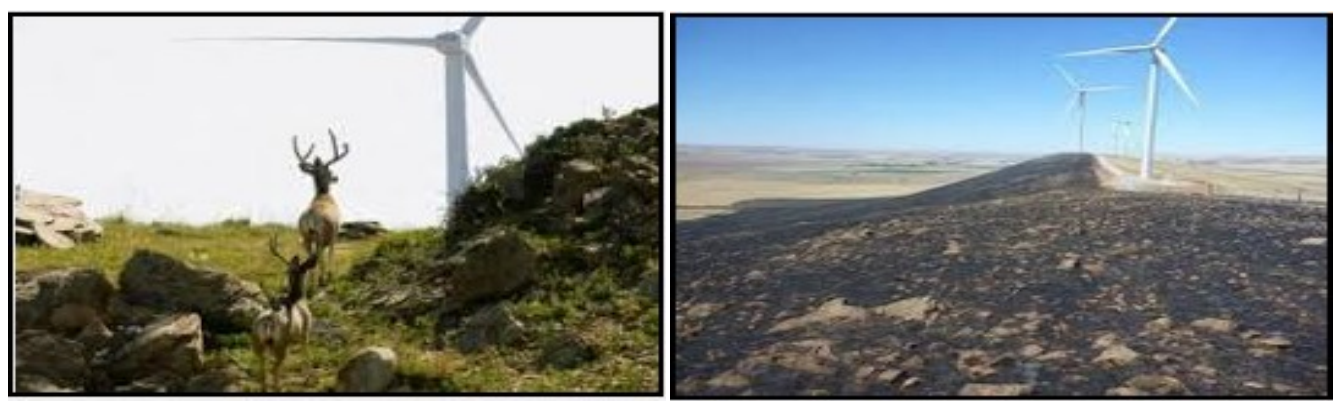

Figure 7: Wind farms and Erosion of land area

\section{(VII) Spacing between the turbines:}

On most horizontal wind turbine farms, a spacing of about 6-10 times the rotor diameter is often upheld. However, for large wind farms distances of about 15 rotor diameters should be more economically optimal, taking into account typical wind turbine and land costs (fig. 8 below) [8] [12].
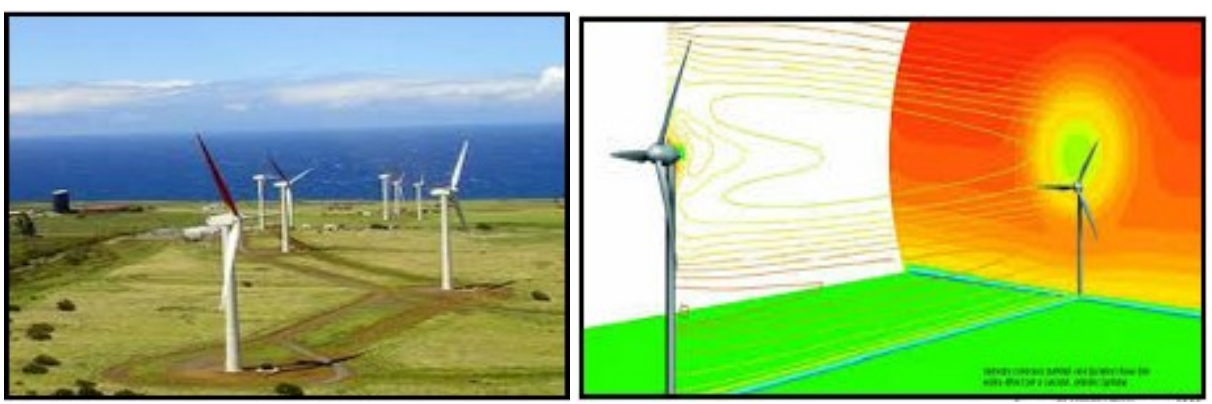

Fig:8 Spacing between the turbines 
(VII)The useful land between the turbines:

Wind farms are spaced over a large geographic area, but their actual "footprint" covers only a small portion of the land resulting in a minimum impact on crop production (fig.9 below).[9]
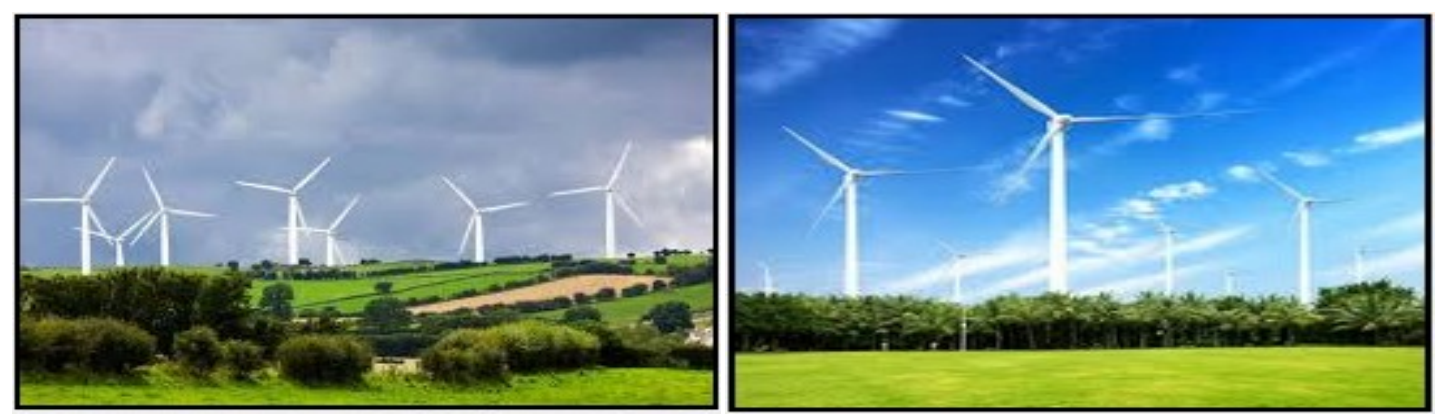

Fig:9 The land in-between can be used for agriculture

\section{(ix)Ecological Impacts:}

There are, nonetheless, ecological impacts that need to be taken into account when assessing wind energy (fig. 10 below). Potential ecological impacts of concern for onshore wind power plants include the population-level consequences of bird and bat collision fatalities and more indirect habitat and ecosystem modifications. [10]
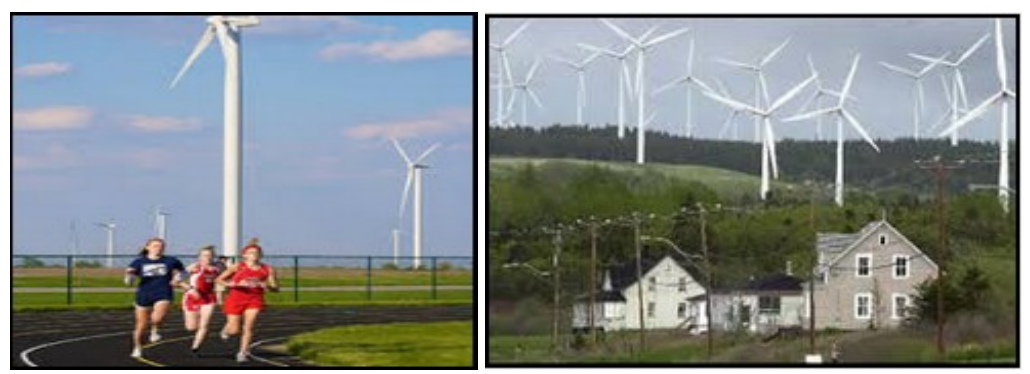

Figure 10: Wind farms and ecological impacts

For offshore wind energy, the aforementioned impacts as well as implications for benthic resources, fisheries and marine life more generally must be considered. Finally, the possible impacts of wind energy on the local climate have received attention. [11][13]

The focus here is on impacts associated with wind power plants themselves, but associated infrastructure also has impacts to consider (e.g., transmission lines, transportation to site etc.).

In addition, though more systematic assessments are needed to evaluate the relative impacts of different forms of energy supply, especially within the context of the varying contributions of these energy sources towards global climate change.

\section{(X)Health and Safety:}

A variety of proximal 'nuisance' effects are also sometimes raised with respect to wind energy development, the most prominent of which is noise. Noise from wind turbines can be a problem, especially for those living within close range. Possible impacts can be characterized as both audible and sub-audible (i.e., infrasound).

There are claims that sub-audible sound, that is, below the nominal audible frequency range, may cause health effects, but a variety of studies government reports have not found sufficient evidence to support those claims to this point. Regarding audible noise from turbines, environmental noise guidelines (EPA, 1974, 1978; WHO, 1999, 2009) are generally believed to be sufficient to ensure that direct physiological health effects (e.g., hearing loss) are avoided.

Some nearby residents, however, do experience annoyance from wind turbine sound which can impact sleep patterns and well-being. This annoyance is correlated with acoustic factors (e.g., sound levels and characteristics) and also with non-acoustic factors (e.g., visibility of, or attitudes towards, the turbines). This may be especially great when hub-height wind speeds are high, but ground-level speeds are low (conditions of high wind shear). 

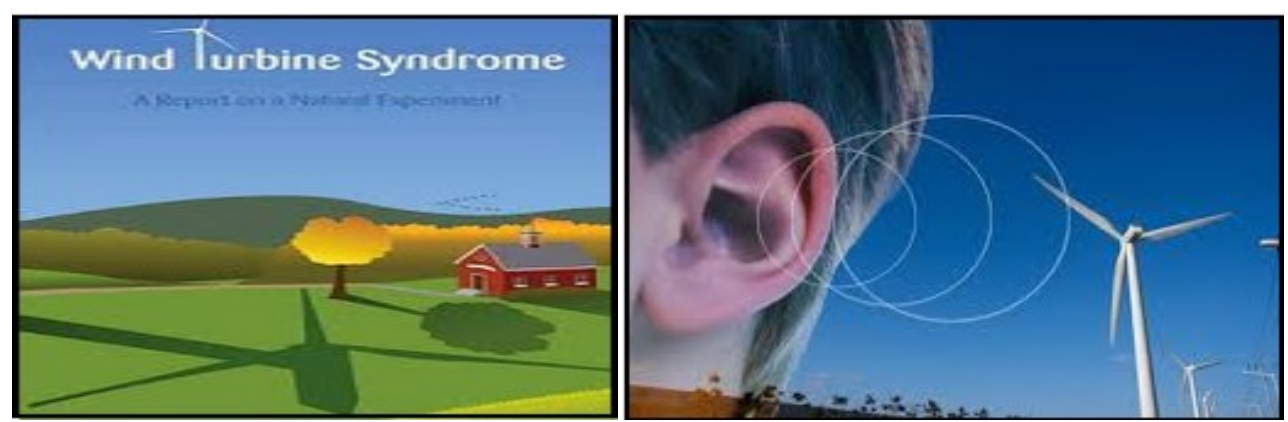

Fig:11 Effect on health due to noise generated by wind farm

Under such conditions, the lack of wind-induced background noise at ground level coupled with higher sound levels from the turbines has been linked to increased audibility and in some cases annoyance Significant efforts have been made to reduce the sound levels emitted by wind turbines. As a result, mechanical sounds from modern turbines (e.g. gearboxes and generators) have been substantially reduced. Aeroacoustic noise is now the dominant, and some of the specific aero acoustic characteristics of wind turbines have been found to be particularly detectable.[14 ]

Reducing aero acoustic noise can be most easily accomplished by reducing blade speed, but different tip shapes and airfoil designs have also been explored In addition, the predictive models and environmental regulations used to manage these impacts have improved to some degree. Specifically, in some jurisdictions, both the wind shear and maximum sound power levels under all operating conditions are taken into account when establishing regulations.

Despite these efforts, concerns about noise impacts remain a barrier to wind energy deployment in some areas. In addition to sound impacts, rotating turbine blades can also cast moving shadows (i.e., shadow flicker), which may be annoying to residents living close to wind turbines. Turbines can be sited to minimize these concerns, or the operation of wind turbines can be stopped during acute periods (Hohmeyeretal, 2005). [15]

Finally, wind turbines can shed parts of or whole blades as a result of an accident or icing (or more broadly, blades can shed built-up ice, or turbines could collapse entirely). Wind energy technology certification standards are aimed at reducing.

\section{Conclusions:}

Over the last decade, wind energy has developed by leaps and bounds. During this period, the world wind power generating capacity has grown rapidly with an average annual growth of $29 \%$. Till December-2013, the totally installed capacity increased to over $200 \mathrm{GW}$, and reached to about $320 \mathrm{GW}$. It is estimated to hit $400 \mathrm{GW}$ by 2014 and $425 \mathrm{GW}$ by 2015 . However, whether or not the development of wind power can maintain this pace and reach the target in the future is, to a large extent, decided by energy policies.

While At present, wind energy is a mature renewable energy source that has high most wind power development is onshore, offshore wind power is a comparatively new sector of wind energy that has attracted people's attention due to its many advantages over onshore wind. European countries have thus far been leading the offshore wind market and technology. As of 2013, the cumulative capacity of offshore wind in Europe reached $3.2 \mathrm{GW}$.

Countries like China, United States and India are also making efforts to develop their offshore wind farms. However, offshore wind is a new technology that still needs to be tested in the tough marine environment, and its specific machines need further development. Although wind power is believed to be environmentally benign, compared to conventional fossil fuels, it till has effects on social life, such as noise and visual impacts etc.

In recent years, its climatic impact has drawn particular attention. These impacts may seem minor at present, built potential long-term effects are not yet known, and thus cannot be ignored. With the development of wind power, the CFD (Computational Fluid Dynamics) method has been more and more frequently used in a variety of wind project studies, and has been used to predict its environmental impact.

Despite the different social and environmental effects, the wind farm installation proved to be a better resource of energy. It provides an access to power at the remote located areas, the job opportunities as well as saving of fossil fuels. 


\section{References}

[1]. MNRE accessed at http://bit.ly/14woYJX (2014).

[2]. L. Harrrison, "Wind rock solid as uncertainly reigns," Wind Power, pp.52-53, 2009.

[3]. Gadgil, M., Krishnan, B., Ganeshaiah, K., Vijayan, V., Borges, R., Noronha, L., et al (2011). Western Ghats Ecology Expert Panel. New Delhi: Ministry of Environment and Forests.

[4]. World Wind Energy Assoc. WWEA, "World wind energy report 2008," 8th World Wind Energy Conf. \&Exhibition Wind Power for Islands - Offshore and Onshore, Jeju Island, South Korea, pp. 5-6, June 2009.

[5]. Wind turbines today - Enhanced reliability with dataforth signal conditioners," Dataforth.

[6]. MNRE \& CII. (2010). Human Resource Development Strategies for Indian Renewable Energy Sector. New Delhi

[7]. Wind power and the environment - benefits and challenges" Wind directions, 2006.

[8]. R. Thresher, M. Robinson, and P. Veers "The future of wind energy technology in the united states," 2008 World Renewable Energy Congress, Glasgow, Scotland, UK, July 2008.

[9]. India wind energy outlook 2012

[10]. N. Kautto and A. J. Waldau, "Renewable energy snapshots 2009," Institute for Energy, Renewable Energy Unit, pp. 27-28, Mar. 2009 .

[11]. Offshore wind worldwide (http://www.bwea.com/offshore/worldwide.html

[12]. A. Kusiak and Z. Song, "Design of wind farm layout for maximum wind energy capture" Renewable Energy, Vol. 35, No.3, pp. 685-694, March 2010.

[13]. T. Bhatti and D. Kothari, "New horizons for offshore wind energy: Shifting paradigms and challenges", Energy Sources, Part A: Recovery, Utilization, and Environmental Effects, vol. 27, no. 4, pp. 349-360, Feb. 2005.

[14]. R. Rechsteiner, "Wind power in context - A clean revolution in the energy sector," Energy Watch Group, pp. 11-13, Dec. 2008 (Press Conference of Energy Watch Group).

[15]. "Wind power and the environment - benefits and challenges," The European Wind energy Association, Aug. 2008. 